\title{
Surge Voltage Distribution Test for the Insulation Design at Kihoku Converter Station
}

\author{
Member Toshio Sonoda, Member Masato Yamada (The Kansai Electric Power, Co., Japan) \\ Member Kiyoshi Hasegawa, Member Taizo Hasegawa (The Kansai Electric Power, Co, Japan) \\ Non-Member Takashi Okamoto, Member Satoshi Yasuda (Mitsubishi Electric Corp., Japan) \\ Member Nobuyuki Nakada, Non-Member Masakazu Yokoyama (Hitachi, Lid., Japan)
}

\begin{abstract}
This paper presents the results of the surge voltage distribution test at Kihoku converter station to verify the EMTP simulation modeling. The test voltage applied at the $\mathrm{DC}$ or $\mathrm{AC}$ transmission line entrance of the station. We calculated the voltage distribution of the converter station by EMTP taking the test conditions into consideration in addition to that of prior analyses. The simulated voltage distributions of either side of voltage application case agree very well with those of test results. The accordance shows that the EMTP modeling used in the study was appropriate.
\end{abstract}

Keywords: DC transmission systems, converter station, insulation design, surge voltage test, EMTP model

\section{Introduction}

Recently, the voltages and capacities of $\mathrm{HVDC}^{(1)-(4)}$ power transmission projects are growing higher and larger with the progress of the high power semiconductors. Three electric power companies in Japan of The Kansai Electric Power, Shikoku Electric Power and Electric Power Development have involved in a cooperative work to construct the project "Kii Channel HVDC Link". And Kihoku converter station where the DC power system is interconnected to the $A C$ $500 \mathrm{kV}$ power system of Kansai Electric Power has just begun the commercial operation in end of June 2000 with the rated transmission power of $1400 \mathrm{MW}\left(1^{\text {st }}\right.$ stage). The latest HVDC power transmission technology $y^{(5)-(7)}$ in Japan has been utilized in the design and construction of the system. One line diagram of Kihoku converter station is illustrated in Fig.1.

The various kind of overvoltages ${ }^{(8)}$ caused by lightning, line fault and control circuit failure have been analyzed using EMTP in the design stage, but the actual demonstration data showing the appropriateness of the simulation were insufficient especially as regards to converter stations.

The authors planned to carry out the voltage distribution test in Kihoku converter station just after the completion of the installation work to investigate the performance of EMTP (DCG Ver 1.1) modeling for the lightning surge analysis. We compared the test results with the analyzed one, and confirmed the accordance of both results.

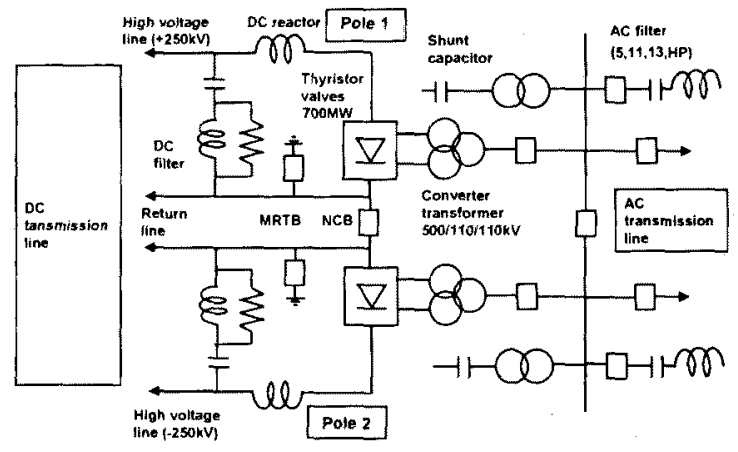

Fig.1 One line diagram of Kihoku converter station

\section{Insulation design}

According to the results of EMTP simulation, LIWV of $750 \mathrm{kV}$ (Ar $\mathrm{V}_{10 \mathrm{kA}}=525 \mathrm{kV}$ ) was selected for the high voltage $\mathrm{DC}$ line side, $400 \mathrm{kV}\left(\mathrm{Ar} \mathrm{V}_{10 \mathrm{kA}}=190 \mathrm{kV}\right.$ ) for neutral line and $311 \mathrm{kV}\left(\mathrm{Ar} \mathrm{V}_{2 \mathrm{kA}}=270 \mathrm{kV}\right.$ ) for that across the thyristor valve. In the design stage, the following three cases of the lightning surges were studied, (1) Direct striking to the DC high voltage line conductor (lightning current $15[\mathrm{kA}]$ ) and (2) Back flash over to the DC neutral line (150 [kA]), and (3) Back flash over to the upper phase conductor of $\mathrm{AC}$ transmission line (150 [kA]). .

In case of direct striking to the DC high voltage line, the peak voltage at the line entrance was $628.8 \mathrm{kV}$. The overvoltage was reduced to around $500 \mathrm{kV}$ by the lightning arrester in the wave tail.

In case of back flash over to the DC neutral line, the peak voltage at the line entrance was $507.8[\mathrm{kV}]$, The overvoltage 
was reduced to around $200[\mathrm{kV}]$ in the wave tail by the arresters for the neutral line as well. The analyzed voltage waveforms at DC line entrance are illustrated in Fig. 2.

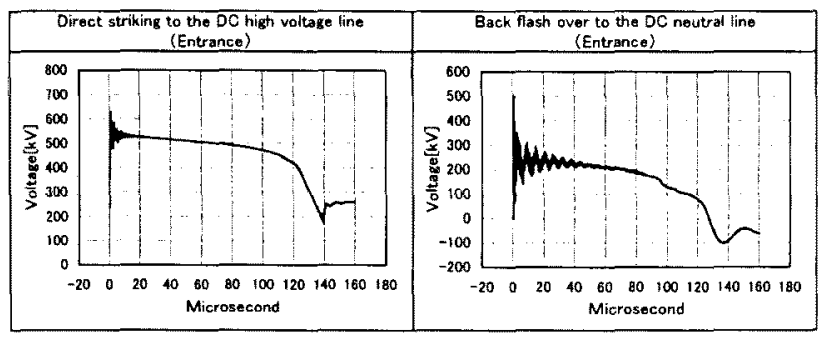

Fig.2 Analyzed waveforms at DC line entrance

\section{Test circuit}

3.1 Voltage application The arbitrary waveform generator (AWG) capable of generating around 100 [V] through the power amplifier was used to apply test voltages. The output voltage waveforms of AWG are set to be same as those calculated by EMTP in order to take the actual lightning phenomena into consideration in the test.

In studied cases at the design stage, lightning arresters were considered to operate and make effect on the overvoltage peak values. But in the voltage distribution test, installed lightning arresters would not actually operate, because the applied voltage is about $100[\mathrm{~V}]$ and lower enough than the discharge inception voltage of installed arresters. We changed the calculation conditions not to let the arrester operate like followings; (1) Direct striking to the DC high voltage line (lightning current $1[\mathrm{kA}]$ ) and (2) Back flash over to the DC neutral line (15 [kA]), and (B) Back flash over to the upper $A C$ phase conductor (15 $[\mathrm{kA}])$. And these calculated voltage waveforms at $\mathrm{DC}$ or $\mathrm{AC}$ transmission line entrance of the station were normalized to be $100[\mathrm{~V}]$ in the peak value and used as the input signal to AWG to generate the same voltage in the test. Voltage application point in the test were set at following three points of transmission line entrances of the station. (1) High voltage side of the DC line (2) Neutral side of the DC line (3) Phase A conductor of the AC line. An example of the applied voltage waveforms used in the test is illustrated in Fig. 3.

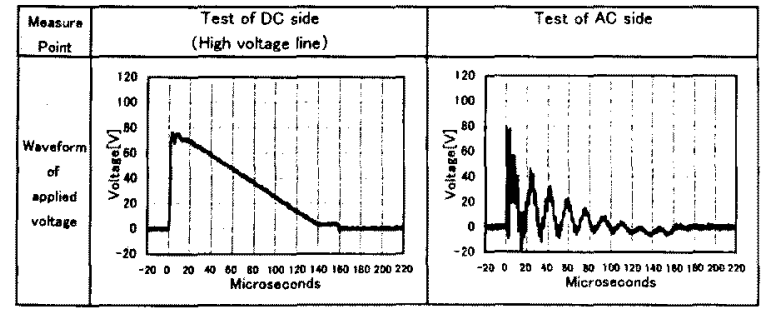

Fig.3 Applied voltage waveforms in the test
3.2 Voltage application test from DC side The test voltages were applied at the DC line entrance, which propagated toward the converter station. The bus configuration was a monopolar operation mode. The voltage application point of the high voltage DC line side or neutral side and the ON/OFF state of the thyristor valves were taken into consideration as the test conditions. And all of the open line terminals other than the voltage application line were grounded through matching resistance.

The test cases are shown in Table 1, and the test circuit of voltage application from the DC side is illustrated in Fig. 4 (a), the turn on state of the thyristor valves in Fig. 4 (b). The line switch (LS) of the $A C$ side of the converter transformer was opened. The turn on state of the thyristor valves were represented by short circuiting across the valves with the wires, and voltage drop can be neglected compared with the test voltage of around $100[\mathrm{~V}]$.

Table 1 Test cases of voltage application from DC side

\begin{tabular}{|c|c|c|c|}
\hline Operation & $\begin{array}{c}\text { Applied } \\
\text { point }\end{array}$ & $\begin{array}{c}\text { Thyristor } \\
\text { valve }\end{array}$ & $\begin{array}{c}\text { case } \\
\text { No. }\end{array}$ \\
\hline Monopolar & $\begin{array}{c}\text { High } \\
\text { voltage }\end{array}$ & OFF & D1 \\
\cline { 2 - 4 } & Neutral & ON & D2 \\
\cline { 2 - 4 } & Neut \\
\hline
\end{tabular}

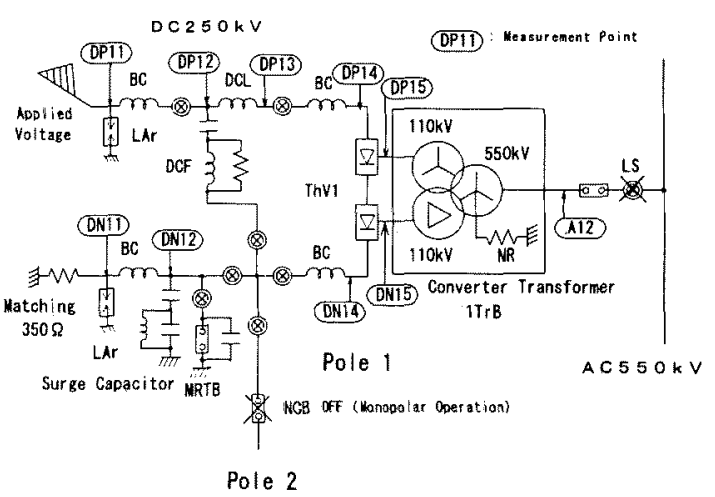

(a) Test circuit

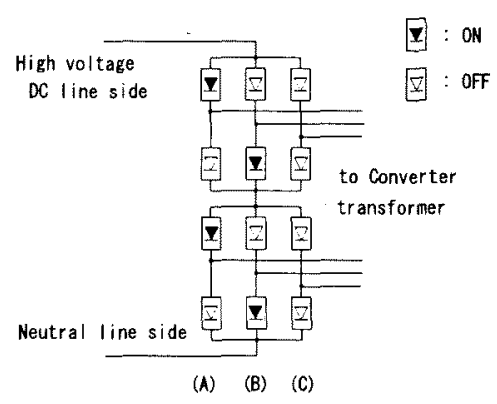

(b) Turn on state of the thyristor valves

Fig.4 Test circuit of voltage application from DC side 
3.3 Voltage application from AC side $500 \mathrm{kV}$ bus section circuit breaker $(C B)$ was open state (OFF) in case of monopolar operation. The ON /OFF state of the $\mathrm{CBs}$ for the equipment such as shunt capacitors and $\mathrm{AC}$ filters ( $\mathrm{SC} / \mathrm{ACF}$ ) and the thyristor valves were taken into consideration as the test conditions. The voltage application point was at \#1 line of Minami-Yamato line (phase A), and other phases of AC and DC line terminals were grounded through the matching resistance of $350 \mathrm{Ohm}$.

The test circuit of voltage application from the AC side is illustrated in Fig.5, and test cases are shown in Table 2. The turn on state of the thyristor valves is same condition as DC side test.

Table 2 Test cases of voltage application from AC side

\begin{tabular}{|c|c|c|c|c|}
\hline Operation & $\begin{array}{l}\text { Applied } \\
\text { point }\end{array}$ & $\begin{array}{c}\text { Thyristor } \\
\text { valve }\end{array}$ & SC/ACF & $\begin{array}{l}\text { case } \\
\text { No. }\end{array}$ \\
\hline \multirow[t]{3}{*}{ Monopolar } & \multirow{3}{*}{$\begin{array}{c}\text { Minami- } \\
\text { Yamato } \\
1 \mathrm{~L}\end{array}$} & OFF & Separated & A1 \\
\hline & & \multirow[t]{2}{*}{$\overline{O N}$} & Separated & $\overline{A 2}$ \\
\hline & & & Connected & A3 \\
\hline
\end{tabular}

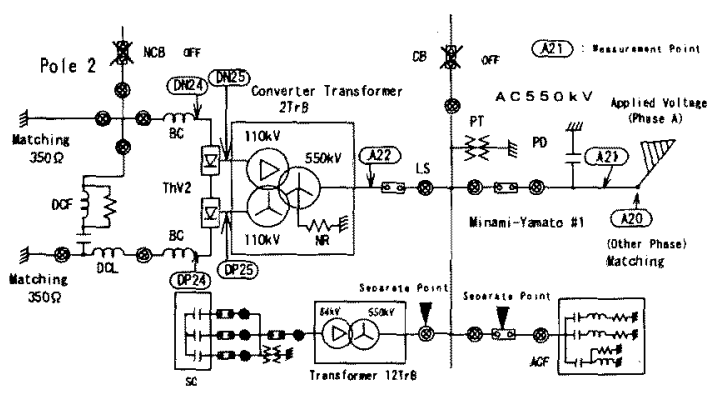

Fig.5 Test circuit of voltage application from $A C$ side

\section{Test results}

4.1 DC side voltage application Measured voltage distributions of high voltage DC line side application (case D2) and neutral side (case D3) are shown in Fig. 6 (a) and Fig. 6 (b) respectively. They are results for the case of the ON state thyristor valves. DP15 (A) and DN15 (A) in Fig.6 are measurement points of phase $A$ of three phase converter transformer.

There is an oscillation in the wave front of the voltage at the point DP12 shown in Fig. 6 (a) that is DC transmission line side of the $D C$ reactor (DCL). The peak voltage at the thyristor valve side of the DCL (point DP13) is rather low. The voltage distribution shown in Fig. 6 (b) differs from that shown in Fig. 6 (a) due to voltage application point, and the waveform at the point DNI2 in Fig. 6 (b) has an oscillation that is attenuated about in 3 cycles with the period of around $40 \mu \mathrm{s}$. The voltages at the other point than DN11, DN12 are relatively low and the wave shapes are almost same.

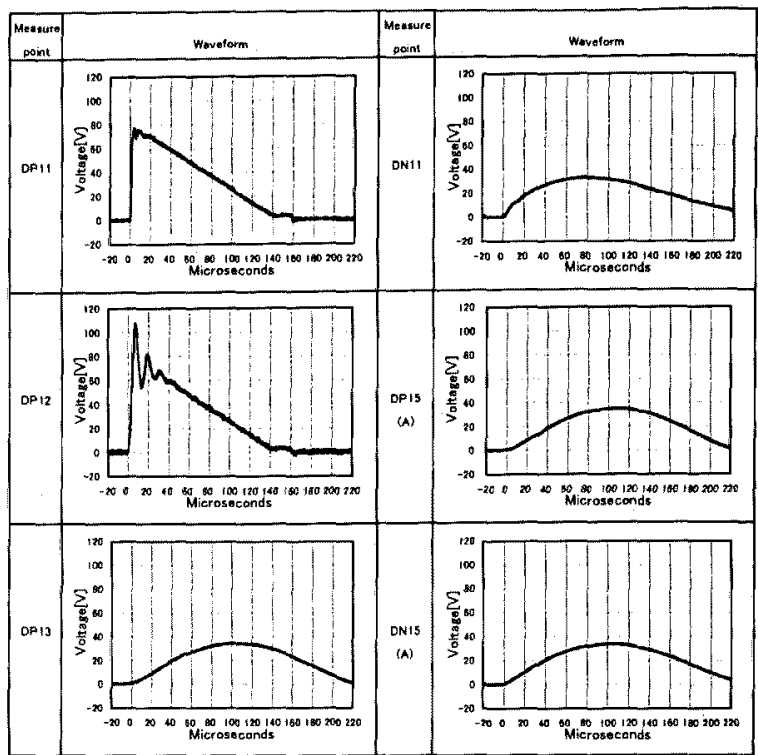

(a) Applied to HV DC line, valve ON (Case D2)

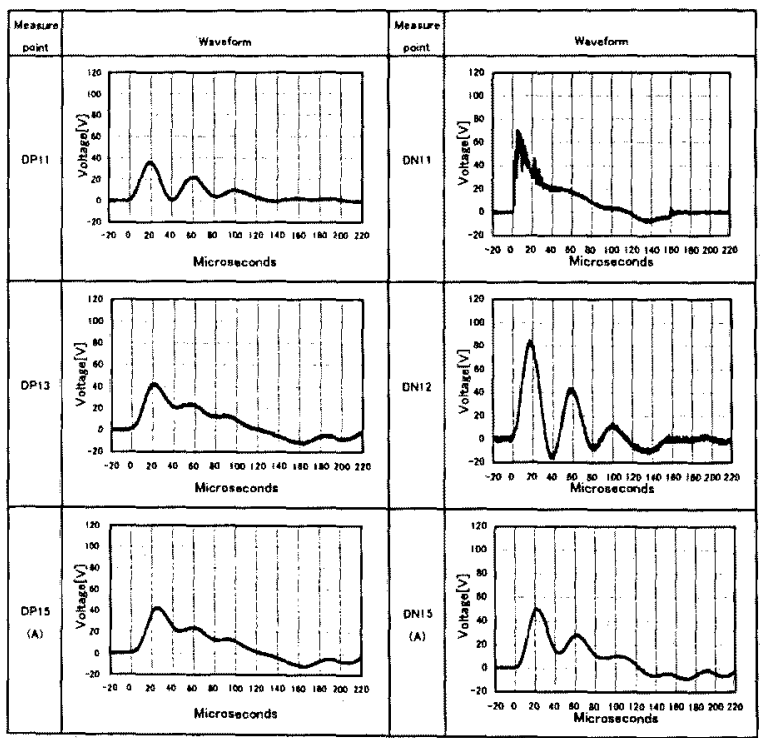

(b) Applied to neutral line, valve ON (Case D3)

Fig. 6 Measured results of DC side voltage application

4.2 AC side voltage application Measured results of case $A 2$ are shown in Fig. 7. The test case $A 1$ and $A 2$ were executed to examine the effect of ACF/SC connection on the voltage distribution though the configuration is not actual one in ordinary DC system operation.

The waveforms at point A21 and A22 in Fig. 7 are oscillatory and superimposed oscillation component is larger than that of applied voltage. The transfer voltages from $\mathrm{AC}$ 
side to DC side are measured at point DP25 and DN25, and they are very small, about 0.1 times the voltage at $\mathrm{A} 22$.

In case A3, the waveform at point A21 attenuates about in 3 cycles, because of the increase in the total capacitance to ground by connecting SC/ACF to the test circuit. Damping factor of voltage oscillation of $A 21$ is greater than that of case $\mathrm{A} 2$ due to the capacitance of the SC/ACF.

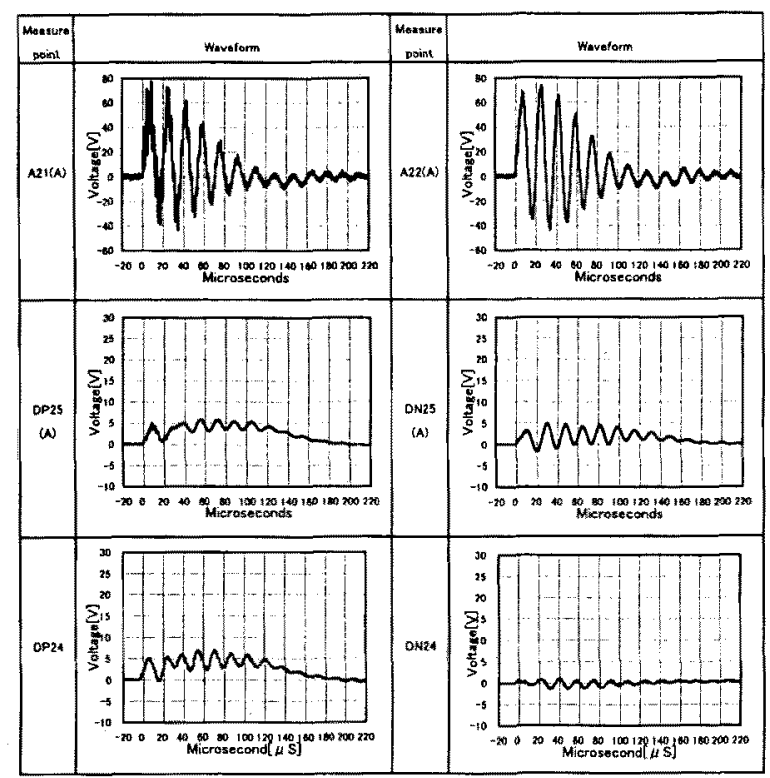

Fig. 7 Measured results of $A C$ side ( Case A2) (Monopolar operation, SC/ACF: OFF, Valves: ON)

\section{Discussion}

The test results of voltage application test from $D C$ side are shown in Fig. 8 (a) and Fig. 8 (b), and that from $\mathrm{AC}$ side is shown in Fig. 9. The measured voltages are normalized by applied voltage.

The voltage distribution is dependent on the selection of the voltage application point the high voltage side or neutral side of DC line.

The followings are made clear by voltage application test from $D C$ side.

a. When the test voltage is applied to the high voltage DC line, the maximum voltage produces at the point DP12 (about 1.4 times the applied peak voltage).

b. And measured voltage at the point DPI3, which is at the thyristor valve side of the DCL is $0.3 \sim 0.5$ times the applied voltage at maximum.

c. When the test voltage is applied to neutral DC line, the maximum voltage produces at DN 12 the installation point of the surge capacitor (about 1.2 times the applied peak voltage). The maximum voltage of the other points are in the range of $0.5 \sim 0.7$ times the applied voltage.
In the case that the voltage applied at the high voltage $D C$ line side, a local oscillation loop is made up of $A W G$, blocking coil and stray capacitance to ground provided mainly by DC filter. The resonance frequency of the loop has good accordance with the oscillation frequency of voltage wave shape at DPI2 shown in Fig. 6 (a). The reason why the peak voltage of DP12 is 1.4 times higher than the applied voltage is supposed to be the superimposition of local oscillation on the applied voltage.

In the case of neutral line voltage application, the local oscillation loop consists of AWG, blocking coil and surge capacitor. The resonance frequency is rather low compared with that of high voltage side application and accords with that of voltage wave shape at DN12 shown in Fig.6 (b).

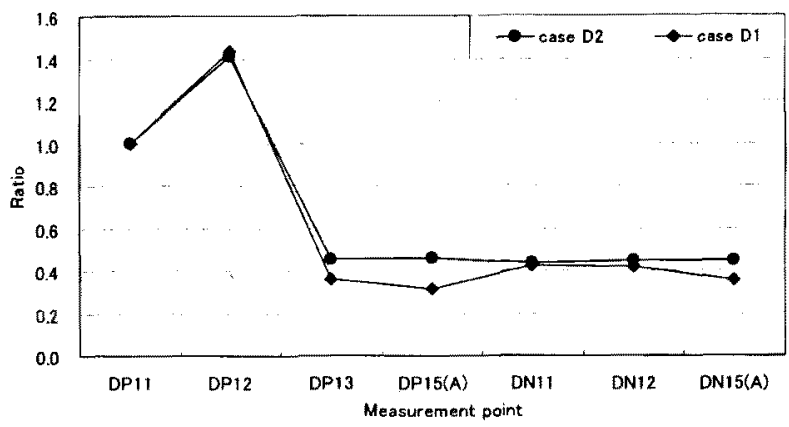

(a) Voltage application to high voltage DC line

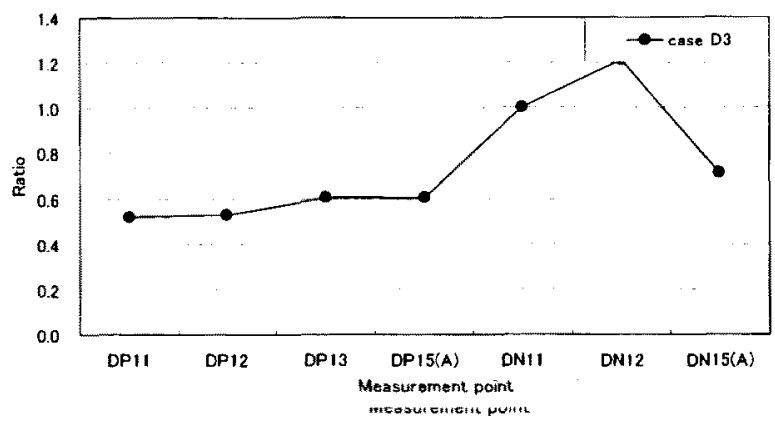

(b) Voltage application to Neutral DC line

Fig. 8 Resume of Measured Voltage distribution

Followings are made clear by $\mathrm{AC}$ side voltage application test.

a. The connection of $\mathrm{SC}$ and $\mathrm{ACF}$ to the test circuit well reduces the voltage at the points $\mathrm{A} 21$ and $\mathrm{A} 22$ to 0.6 $\sim 0.75$ times the applied voltage.

b. The rate of the transfer voltage from $\mathrm{AC}$ side to $\mathrm{DC}$ is rather small (around 0.1 times the application voltage).

The connection of SC/ACF to the circuit supposed to reduce the peak voltage owing to their large capacitance. 


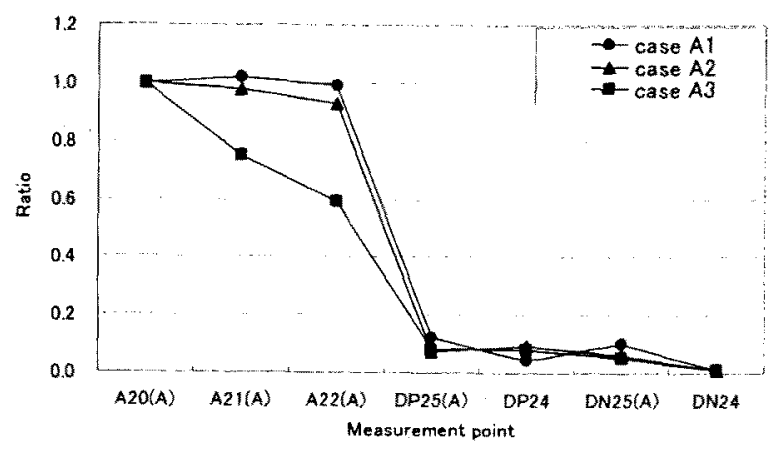

Fig. 9 Resume of Measured Voltage distribution (AC side voltage application)

\section{Analysis after the test}

6.1 EMTP model We calculated the voltage distribution again by EMTP taking following change of study conditions into consideration in addition to the prior analyses.

i The waveform of the applied voltage in the test was modeled by the voltage source at the voltage application point.

ii DCF and converter transformer was modeled in detail considering their stray capacitance's.

The models of the thyristor valves and converter transformer are illustrated in Fig. 10 (a) and Fig. 10 (b).

6.2 Analysis results A comparison between the reanalyzed and test results is shown in Fig. 11 (a) for the case D2, in Fig. 11 (b) for the case A2.

There is almost no difference between the test and analyzed waveforms on the viewpoints of peak values and the oscillation waveform. Especially, the analyzed results of DC side voltage application become closer to the test results due to consideration of the stray capacitance mainly provided by $\mathrm{DC}$ filter.

\section{Conclusion}

We carried out the surge voltage distribution test at the Kihoku converter station applying the test voltage by the arbitrary wave generator in order to verify the appropreateness of EMTP modeling which was utilized to decide the insulation levels in the design stage. EMTP simulated results made by reflecting carefully the test condition agree very well with the test results in either case of $D C$ and $A C$ side voltage application.

Therefore it can be concluded that the EMTP modeling is confirmed to be adequately reasonable.
(Manuscript received December 25, 2000, revised Apri\} $18,2001)$

\section{References}

[1] HVDC handbook, "Insulation coordination", EPRI Publication No. TR-104166, 1994 Section 14

[2] "Bibliography on overvoltage protection and insulation coordination of HVDC converter stations", IEEE WG 3.4.6, lbid., pp. 744-753

[3] "Handbook for insulation coordination of high-voltage DC converter stations", EPRI report No. EL-5414, Oct 1987

[4] "Application guide for insulation coordination and arrester protection of HVDC converter stations", CIGRE WG 33.05, Electra No. 96, Oct 1984, pp.101-156

[5] Y.Sekine et al., "Kii channel HVDC L link between Shikoku and Kansai electric power companies by submarine cables", CIGRE Symposium Tokyo, 1995, 220 04

[6] T.Hasegawa et al., "Design of $\pm 500 \mathrm{kV}$ compact converter stations of the Kii channel HVDC link", CIGRE Symposium Tokyo, 1995, 420-05

[7] T.Hasegawa et al., "System design of Kii channel HVDC link", CIGRE Session Paris, 1996, 14-103

[8] S. Sasaki, et al., "Transient overvoltages and overcurrents during line fault tests on the Hokkaido-Honshu HVDC link", IEEE Trans. PAS, Vol. PAS-101, No.8, 1982, pp. 2476-2484

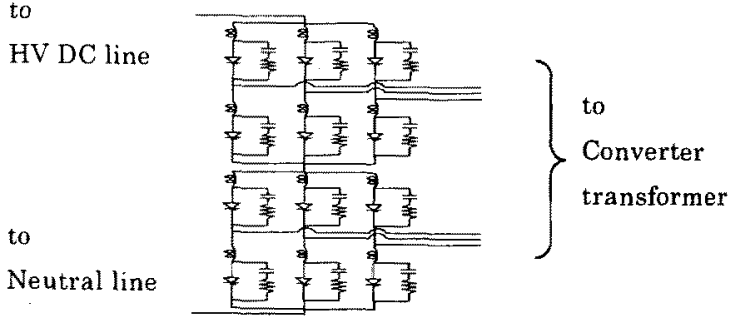

(a) Thyristor valve

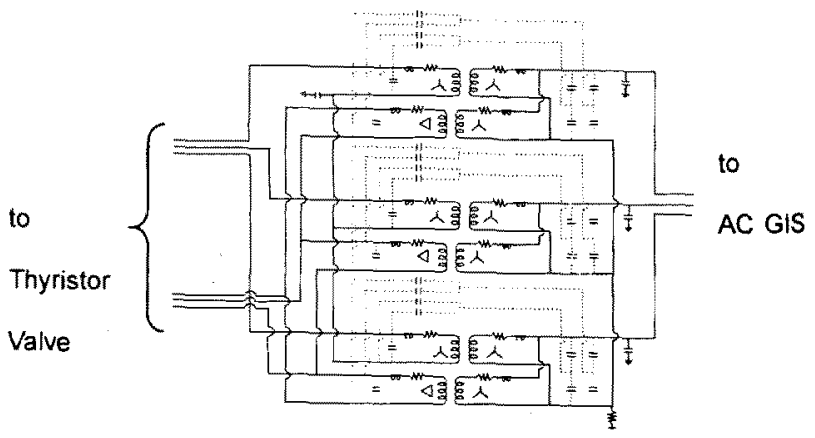

(b) Converter transformer

Fig. 10 EMTP analysis model of typical DC equipment 


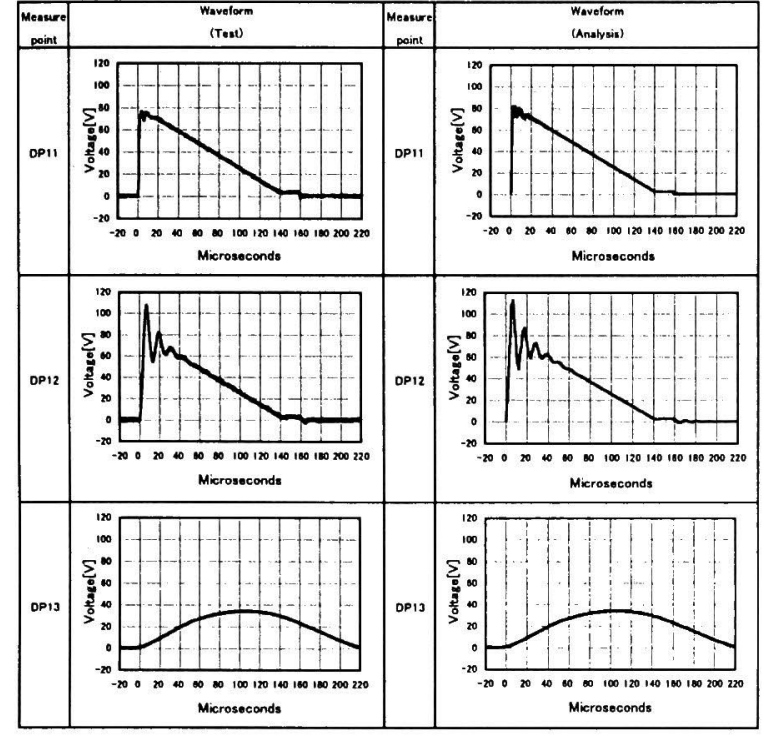

(a) DC side voltage application

(Applied to high voltage DC line, valve $\mathrm{ON}$ )

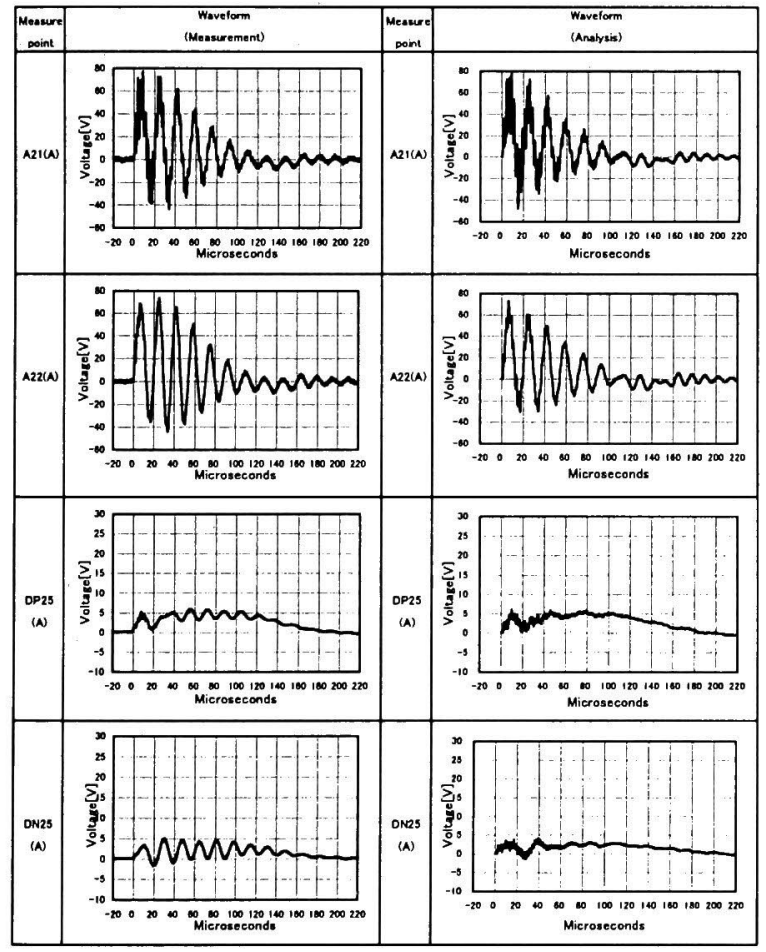

(b) AC side voltage application

(SC/ACF separated, valve ON)

Fig.11 Comparison of test and analyzed results

Toshio Sonoda (Member) was born on July 15, 1965. He joined The

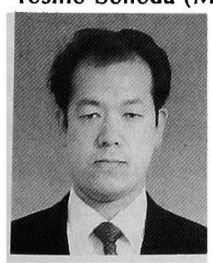

Kansai Electric Power Co. Inc., Osaka, Japan in 1984, and has engaged in the research of the power systems.
Masato Yamada (Member) was born on July 22, 1964. He received

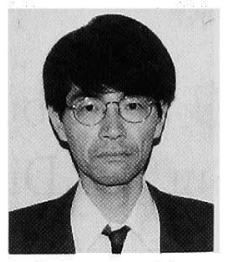

the M. S. degree in electrical engineering from Kobe University, Japan, in 1989. He joined The Kansai Electric Power Co. Inc., Osaka, Japan in 1989 , and has engaged in the research of the power systems and superconducting machine

Kiyoshi Hasegawa (Member) was born on May 31, 1952. He

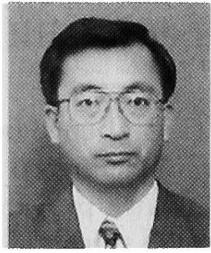
received the M. S. degree in electrical engineering from Osaka University, Japan, in 1977. He joined The Kansai Electric Power Co. Inc., Osaka, Japan in 1977, and has engaged in the research of the superconducting machine.

Taizo Hasegawa (Member) was born on February 22, 1947. He

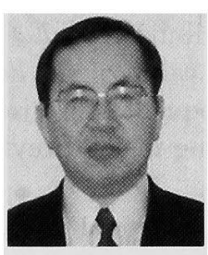
received the $M$. $S$. degree in electrical engineering from Osaka University, Japan, in 1971. He joined The Kansai Electric Power Co. Inc., Osaka, Japan in 1971, and has engaged in the research of the DC transmission systems. He is a president in Technical Research Center.

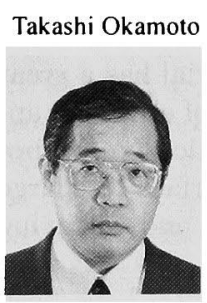

(Non-Member) was born on January 29, 1953. He graduated from Osaka Prefectural Technical College in 1973. He joined Mitsubishi Electric Corporation in 1973. He has been involved in the system engineering of power systems.

Satoshi Yasuda

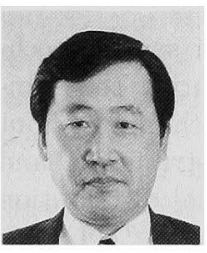

(Member) was born on October 13, 1950. He received the B.S. degree in electrical engineering from Osaka University in 1975. He joined Mitsubishi Electric Corporation in 1975. He has been involved in the system engineering of power systems.

Nobuyuki Nakada (Member) was born on December 27, 1958. He

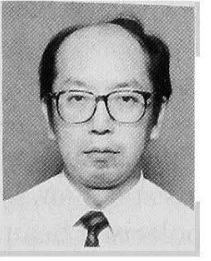
received the B.S. degree in Electrical Engineering from Tokyo Denki University, Japan, in 1981. He joined Power \& Industrial Systems Division of Hitachi Ltd, Japan. He has engaged in Quality Assurance of Large Power Transformers.

Masakazu Yokoyama (Non-Member) was born on August 11, 1966

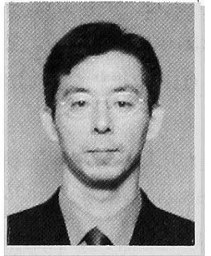
He received the M.S. degree in Electrical Engineering from Nagoya Institute of Technology, Japan, in 1991. He joined Power \& Industrial Systems Division of Hitachi Ltd, Japan in 1991. He has engaged in Designing \& Development of Large Power Transformers. 